\title{
A prospective study of maternal postnatal depressive symptoms with infant-feeding practices in a Chinese birth cohort
}

Tingting Sha, Xiao Gao, Cheng Chen, Ling Li, Gang Cheng, Xialing Wu, Qianling Tian, Fan Yang, Qiong He and Yan Yan* (1)

\begin{abstract}
Background: The first few weeks after childbirth are critical, as women may encounter lactation problems and postpartum depression during this period. However, it is still unclear whether early breastfeeding behaviours are related to the symptoms of postnatal depression (PND) in Chinese populations. Therefore, the current study aimed to investigate the association between symptoms of PND and infant feeding practices based on a large-scale Chinese cohort.

Methods: A prospective study of the community-based cohort was conducted from January 2015 to December 2016. Infant feeding outcomes, including exclusive/partial breastfeeding and formula feeding, were assessed according to the WHO guidelines. Symptoms of PND were assessed by the Edinburgh Postnatal Depression Scale at 4 weeks postpartum. Multivariate generalized estimating equation models were applied to investigate the associations between depressive symptoms and infant feeding behaviours.

Results: A total of 956 mother-infant pairs were included. Fifty-six mothers presented screen-positive symptoms of PND with a cut-off $\geq 10$. The percentage of early breastfeeding initiation was $75.8 \%$, while the average duration of exclusive breastfeeding was $3.90 \pm 2.33$ months. Postnatal depressive symptoms were associated with a shorter breastfeeding duration ( 8.02 vs. 6.32 months, $P<0.05)$ and earlier formula introduction (4.98 vs. 3.60 months, $P<$ 0.05). After adjustments were made for covariates, postnatal depressive symptoms were associated with an increased risk of the discontinuation of exclusive and partial breastfeeding $(\beta=-0.049, P=0.047$ and $\beta=-0.082$, $P=0.006$, respectively). Compared to mothers without symptoms of PND, mothers with depressive symptoms were more likely to supplement formula for their infants in the first year of life $(\beta=0.074, P=0.016)$. These associations were still significant in the sensitivity analyses, using an EPDS cut-off of $\geq 13$.
\end{abstract}

Conclusions: Our findings indicate that depressive symptoms at 4 weeks postpartum are associated with the cessation of exclusive and partial breastfeeding duration and the introduction of formula in the 12 months of delivery. Early psychosocial assessment and social support should be offered to mothers in the early postpartum period to indirectly prevent adverse breastfeeding outcomes.

\footnotetext{
* Correspondence: yanyan802394@126.com

Department of Epidemiology and Medical Statistics, Xiangya School of Public

Health, Central South University, Changsha, Hunan, China
}

(c) The Author(s). 2019 Open Access This article is distributed under the terms of the Creative Commons Attribution 4.0 International License (http://creativecommons.org/licenses/by/4.0/) which permits unrestricted use, distribution, and reproduction in any medium, provided you give appropriate credit to the original author(s) and the source, provide a link to the Creative Commons license, and indicate if changes were made. The Creative Commons Public Domain Dedication waiver (http://creativecommons.org/publicdomain/zero/1.0/) applies to the data made available in this article, unless otherwise stated. 


\section{Background}

At present, an estimated $10-15 \%$ of women experience depressive symptoms during the postpartum period [1]. Postnatal depression (PND) is a severe mental disorder that is often characterized as a persistent low mood in new mothers [2]. The Diagnostic and Statistical Manual for Mental Disorders-Fifth Edition defines depression with peripartum onset as occurring during pregnancy or within the first 4 weeks postpartum [3]. Emerging research suggests that PND is associated with a series of adverse effects on obstetric and perinatal outcomes, such as infant behaviours, cognition or growth development, and maternal-infant interaction [4-7].

Breastfeeding is the optimal way to nourish and nurture babies; it is beneficial to both infants and mothers in the short and long term [8]. The World Health Organization (WHO) and many other authorities recommended that infants be exclusively breastfed for the first 6 months after delivery and should be continuously breastfed for at least 1 year [9]. However, only one-third of children globally are exclusively breastfed from 0 to 6 months, which is far from the recommendation $[10,11]$.

The low rate of exclusive breastfeeding during the first 6 months highlights the importance of exploring factors that might potentially affect breastfeeding practices. Depression in the early postpartum period is an important factor $[12,13]$. However, research investigating the relationship between breastfeeding and postpartum depressive symptoms shows mixed results. Data from previous systematic reviews have indicated that PND was associated with early breastfeeding cessation, decreased breastfeeding duration, and increased breastfeeding difficulties $[14,15]$. For instance, the result of a prospective study suggested that mothers with PND seem to promote the discontinuation of breastfeeding at 5 months postpartum [16]. Researchers also found that depressive symptoms at 1 week postpartum were associated with the discontinuation of breastfeeding at 4 and/or 8 weeks postpartum and an increased risk of breastfeeding problems [17]. Moreover, in a large prospective study of postpartum women, the authors found that depression at 2 weeks postpartum was associated with the cessation of breastfeeding at 12 weeks postpartum [18]. However, other prospective studies found no association between PND and breastfeeding [19-22]. A cohort study of 429 infants reported that PND was not associated with the interruption of exclusive breastfeeding at 2 months postpartum ( $R R=1.44 ; 95 \% C I: 0.68-3.06)$ [23]. Based on the cross-lagged panel design, a recent prospective study examined the bidirectional association between breastfeeding and postpartum depression and found no evidence of relationships between them [24].

The conflicting results may be primarily attributed to several methodological limitations [25] or variations in the measurements used to assess breastfeeding and perinatal symptoms [24]. Most studies investigating this association were secondary data analyses, cross-sectional designs or retrospective designs. Moreover, some studies did not continue to the end of the children's first year of life. Additionally, any level of breastfeeding was considered rather than the categorization of breastfeeding as exclusive or partial [26].

In China, the prevalence of children with exclusive breastfeeding for the first 6 months is only 17\% [27], and the duration of breastfeeding is insufficient [28]. Moreover, the available results suggested that a range of 4.70 to $43.12 \%$ of mothers in China experience PND $[29,30]$. The first weeks after childbirth are critical, as women may experience lactation problems and postpartum depression during this period. However, it is still unclear how early breastfeeding experiences are related to postpartum depression in Chinese populations. Therefore, the aim of this study was to examine the associations between symptoms of PND during the first 4 weeks postpartum and infant feeding practices based on a prospective study of a longitudinal birth cohort in China.

\section{Methods \\ Participants}

This study was based on an in-progress communitybased birth cohort study that is conducted in three community health service centres (CHSCs) in Changsha, a capital city of Hunan Province. Maternal and child health care records in Changsha are available in electronic form from the Community Health Management Information System (CHMIS) of Hunan Province. The baseline survey was performed at 1 month postpartum from 1 January 2015 to 31 December 2015, and the follow-up surveys were conducted during infants' regular check-ups at the ages of 3 months, 6 months, 8 months and 12 months. Information was collected via face-toface interviews conducted in the participants' residences. The samples included in the final analysis were restricted to respondents who were permanent residents of Kaifu District, delivered live-born babies during the study period, provided complete healthcare records in the CHMIS, completed the assessment of PND, had no history of mental illnesses or brain diseases, agreed to participate in the study, and signed the written informed consents.

\section{Measures}

Breastfeeding outcomes were assessed according to WHO-recommended definitions. Early breastfeeding initiation was defined as the provision of breast milk to infants within $1 \mathrm{~h}$ of giving birth, as recommended by the WHO [31]. Exclusive breastfeeding was defined as infants being fed with breast milk only, without any 
additional food or drink, not even water (allowable exceptions were expressed breast milk, oral rehydration solutions, and drops or syrups of vitamins, minerals, and medicines) [32]. Partial breastfeeding suggested that infants were fed breast milk regardless of whether they were provided with formula or complementary food. Formula feeding was defined as infants being fed with any formula. Complimentary food introduction was defined as infants being given solid or semi-solid food [33].

The Diagnostic and Statistical Manual for Mental Disorders-Fifth Edition defines postpartum depression as occurring within the first 4 weeks postpartum [3]. Maternal depressive symptoms were assessed at 4 weeks postpartum. The ten-item Edinburgh Postnatal Depression Scale (EPDS) is a simple and reliable screening instrument for the early detection of depression in the postnatal period, and this instrument has been extensively used worldwide. In this study, we assessed the symptoms of PND using the revised Chinese version of the EPDS, which has been demonstrated to have satisfactory psychometric properties [34]. Mothers reported on how often they experienced a symptom of depression in the past week on a four-point scale, with a total score ranging from 0 to 30 . To identify and screen for probable postnatal depressive symptoms, a cut-off of $\geq 10$ was used in this study. This cut-off value has been recommended as an optimum cut-off score when screening for clinical postpartum depression in Chinese mothers in Hong Kong [34] and mainland China [35, 36]. A cut-off of $\geq 10$ has been also extensively used to screen for minor depression in English-speaking women [37, 38]. Moreover, we also performed sensitivity analyses using a cut-off of $\geq 13$, which is usually recommended when screening for major postpartum depression [39]. Cronbach's alpha coefficient for the EPDS was 0.86 in the present study.

\section{Data collection}

The self-designed questionnaire, as well as maternal and child health care records in the CHMIS, were used to collect relevant information through face-to-face interviews conducted by trained investigators during infants' regular check-ups. Daily infant feeding practices were collected by their mothers at 1, 3, 6, 8 and 12 months postpartum. Mothers were asked the following questions to measure infant feeding practices at each time point: 1) whether infants were fed breast milk; 2) whether infants were fed with any formula; 3 ) whether infants were fed with any complimentary food. Women were also asked to report the time of the cessation of breastfeeding, the introduction of formula, and the introduction of complementary food. Data on the early initiation of breastfeeding were collected by asking mothers the following question: "Did you initiated breastfeeding within one hour after delivery?"

Based on the previous literature [40], the following potential confounding factors that might affect infant feeding practices were identified and assessed: maternal age $(<25,25-29,30-34$ or $\geq 35$ years), maternal educational attainment ( $\leq$ junior school, senior school or $\geq$ college), household income per month $(<2000,2000-5000$, $5001-10,000$ or $>10,000$ yuan), pre-pregnancy BMI $(<$ $18.5,18.5-23.9, \geq 24 \mathrm{~kg} / \mathrm{m}^{2}$ ), passive and active smoking during pregnancy (yes or no), gestational week of birth $(<28,28-36,37-42$ or $>42$ week), mode of delivery (vaginal delivery or caesarean delivery), pregnancy-related complication (yes or no), using feeding bottle/nipple before breastfeeding (yes or no), parity (nulliparous or multiparous), infant gender (male or female) and other health-related factors. Maternal weight and height were measured by trained nurses at the CHSC within the first trimester as the proxies for pre-pregnancy weight and height. Pre-pregnancy BMI was calculated from prepregnancy weight $(\mathrm{kg})$ divided by the square of height (m). Other measures such as multiple births, pregnancyrelated complications, and gestational age were collected by extracting health records from the CHMIS. Information on maternal sociodemographic characteristics and other health-related factors were collected using selfdesigned questionnaires.

\section{Statistical analysis}

Categorical variables were described as frequencies and percentages. Continuous variables were compared using two-sample t-tests or Wilcoxon's signed-rank tests. Chisquare tests or Fisher's exact tests were used to compare the categorical outcomes. Generalized estimating equation (GEE) models were used to compare the feeding outcomes based on the symptoms of PND $(\geq 10)$. Sensitivity analyses were also performed to verify the associations between feeding outcomes and positive screening for major PND using a cut-off $\geq 13$ on the EPDS. All statistical analyses were performed with SAS version 9.4 (SAS Institute, Inc., Cary, NC). Two-tailed $P<0.05$ was considered statistically significant.

\section{Results}

During the study period, a total of 1286 infants were born in the three CHSCs of the Kaifu District in Changsha. Among the study participants, 265 of the dyads were not permanent residents and had no healthcare records in the CHMIS, and 45 of the dyads refused to participate. Ultimately, 976 eligible mother-child dyads were included in the final birth cohort. Twenty of them had missing values on the EPDS. Thus, 956 of the dyads were included in the final analysis. Table 1 shows the baseline characteristics of the mother-child dyads. The 
Table 1 Demographic characteristic of the sample $(N=956)$

\begin{tabular}{|c|c|c|}
\hline Variables & $\mathrm{N}$ & $\%$ \\
\hline \multicolumn{3}{|l|}{ Maternal age (years) } \\
\hline$<25$ & 48 & 5.0 \\
\hline $25-29$ & 441 & 46.1 \\
\hline $30-34$ & 348 & 36.4 \\
\hline$\geq 35$ & 119 & 12.5 \\
\hline \multicolumn{3}{|c|}{ Maternal education attainment } \\
\hline$\leq$ Junior school & 32 & 3.3 \\
\hline High school & 122 & 12.8 \\
\hline$\geq$ College graduate & 802 & 83.9 \\
\hline \multicolumn{3}{|c|}{ Pre-pregnancy BMI ${ }^{a}\left(\mathrm{~kg} / \mathrm{m}^{2}\right)$} \\
\hline$<18.5$ & 4 & 0.4 \\
\hline $18.5-23.9$ & 181 & 18.9 \\
\hline$\geq 24$ & 771 & 80.6 \\
\hline \multicolumn{3}{|c|}{ Household income (yuan) } \\
\hline$<2000$ & 31 & 3.2 \\
\hline $2000-5000$ & 521 & 54.5 \\
\hline $5001-10,000$ & 367 & 38.4 \\
\hline$>10,000$ & 37 & 3.9 \\
\hline \multicolumn{3}{|l|}{ Mode of delivery } \\
\hline Vaginal delivery & 575 & 60.1 \\
\hline Cesarean delivery & 381 & 39.9 \\
\hline \multicolumn{3}{|l|}{ Gestational age (weeks) } \\
\hline$<28$ & 0 & 0 \\
\hline $28-36$ & 46 & 4.8 \\
\hline $37-42$ & 910 & 95.2 \\
\hline$>42$ & 0 & 0 \\
\hline \multicolumn{3}{|c|}{ Pregnancy-related complications } \\
\hline No & 819 & 85.7 \\
\hline Yes & 137 & 14.3 \\
\hline \multicolumn{3}{|c|}{ Active smoking during pregnancy } \\
\hline No & 947 & 99.1 \\
\hline Yes & 9 & 0.9 \\
\hline \multicolumn{3}{|c|}{ Passive smoking during pregnancy } \\
\hline No & 863 & 90.3 \\
\hline Yes & 93 & 9.7 \\
\hline \multicolumn{3}{|l|}{ Parity } \\
\hline Nulliparous & 686 & 71.8 \\
\hline Multiparous & 270 & 28.2 \\
\hline \multicolumn{3}{|c|}{ Screened positive for symptoms of PND (EPDS $\geq 10$ ) } \\
\hline No & 900 & 94.1 \\
\hline Yes & 56 & 5.9 \\
\hline \multicolumn{3}{|c|}{ Screened positive for major PND (EPDS $\geq 13$ ) } \\
\hline No & 927 & 97.0 \\
\hline Yes & 29 & 3.0 \\
\hline
\end{tabular}

Table 1 Demographic characteristic of the sample $(N=956)$ (Continued)

\begin{tabular}{lcc}
\hline Variables & $\mathrm{N}$ & $\%$ \\
\hline Using feeding-bottle/ nipple before breastfed & 791 & 82.7 \\
$\quad$ No & 165 & 17.3 \\
$\quad$ Yes & & \\
Infant gender & 493 & 51.6 \\
$\quad$ Male & 463 & 48.4 \\
Female & & \\
Initiation of breastfeeding (hours) & 725 & 75.8 \\
$<1$ & 118 & 12.3 \\
$1-24$ & 113 & 11.8 \\
\hline 24
\end{tabular}

a $B M I$ body mass index, PND postnatal depression

average age of participants and the number of gestational weeks at delivery were $29.93 \pm 3.45$ years and $38.96 \pm 1.51$ weeks, respectively. The percentage of dyads with an early initiation of breastfeeding was $75.8 \%$. The rates of mothers who screened positive for symptoms of PND (EPDS scores $\geq 10$ ) and who screened positive for major PND (EPDS scores $\geq 13)$ were $5.9 \%(n=56)$ and $3.0 \%(n=29)$, respectively.

Table 2 shows the comparisons of infant feeding practices between mothers with and without depressive symptoms across time. Most of the participants with or without symptoms of PND breastfed their babies in the first month after delivery (89.3\% vs. $97.4 \%)$. More than $70 \%$ of the participants without depressive symptoms breastfed their babies exclusively in the first month postpartum, while the exclusive breastfeeding rate of the mothers with depressive symptoms was $57.1 \%$ in the first month postpartum $(P=0.006)$. The partial breastfeeding rates of mothers with depressive symptoms were significantly lower than the rates of mothers with no depressive symptoms at $1,3,6$, and 8 months postpartum, while this difference was not significant at 12 months postpartum. Compared to mothers without depressive symptoms, mothers with symptoms of PND were more likely to provide the supplementary formula for their infants in the first year of life.

Table 3 presents the partial breastfeeding duration and the time of formula introduction between mothers with PND and mothers without depressive symptoms. The partial breastfeeding duration of the mothers with depressive symptoms was significantly shorter than the duration of the mothers without depressive symptoms (8.02 months vs. 6.32 months, $P=0.008$ ). Compared to the mothers without symptoms of PND, mothers with symptoms of PND were more likely to introduce formula for their infants after giving birth (4.98 months vs. 3.60 months, $P=0.014$ ). 
Table 2 Comparisons of infant feeding practices between mothers with and without symptoms of PND ${ }^{a}($ EPDS $\geq 10)$ at each time point

\begin{tabular}{|c|c|c|c|c|c|c|c|c|c|c|}
\hline \multirow[t]{2}{*}{ Variables } & \multicolumn{2}{|l|}{1 month } & \multicolumn{2}{|l|}{3 months } & \multicolumn{2}{|l|}{6 months } & \multicolumn{2}{|l|}{8 months } & \multicolumn{2}{|l|}{12 months } \\
\hline & $\%(n)^{b}$ & $P$ & $\%(n)$ & $P$ & $\%(n)$ & $P$ & $\%(n)$ & $P$ & $\%(n)$ & $P$ \\
\hline \multicolumn{11}{|l|}{ Exclusive breastfeeding } \\
\hline Overall & $72.9(697 / 956)$ & & $63.4(600 / 946)$ & & $13.7(128 / 932)$ & & & & & \\
\hline with symptoms of PND & $57.1(32 / 56)$ & $<0.01$ & $49.1(27 / 55)$ & 0.02 & $9.4(5 / 53)$ & 0.35 & 0 & - & 0 & - \\
\hline without symptoms of PND & $73.9(665 / 900)$ & & $64.3(573 / 891)$ & & $14.0(123 / 879)$ & & 0 & & 0 & \\
\hline \multicolumn{11}{|l|}{ Partial breastfeeding } \\
\hline Overall & $97.0(927 / 956)$ & & $89.7(848 / 946)$ & & $76.1(709 / 931)$ & & $62.8(582 / 927)$ & & $29.1(265 / 910)$ & \\
\hline with symptoms of PND & $89.3(50 / 56)$ & $<0.01$ & $74.5(41 / 55)$ & $<0.01$ & $56.6(30 / 53)$ & $<0.01$ & $47.2(25 / 53)$ & 0.02 & $23.1(12 / 52)$ & 0.32 \\
\hline without symptoms of PND & $97.4(877 / 900)$ & & $90.6(807 / 891)$ & & $77.3(679 / 878)$ & & $63.7(557 / 874)$ & & $29.5(253 / 858)$ & \\
\hline \multicolumn{11}{|l|}{ Formula feeding } \\
\hline Overall & $27.1(259 / 956)$ & & $36.3(343 / 945)$ & & $55.6(517 / 931)$ & & $68.6(636 / 927)$ & & $85.2(775 / 909)$ & \\
\hline with symptoms of PND & $42.9(24 / 56)$ & $<0.01$ & $28(50.9)$ & 0.02 & $69.8(37 / 53)$ & 0.03 & $84.9(45 / 53)$ & 0.01 & $92.3(48 / 52)$ & 0.14 \\
\hline without symptoms of PND & $26.1(235 / 900)$ & & $315(35.4)$ & & $54.7(480 / 878)$ & & $67.6(591 / 874)$ & & $84.8(727 / 857)$ & \\
\hline
\end{tabular}

${ }^{a}$ PND postnatal depression

${ }^{\mathrm{b}}$ Data are expressed as percentages (numbers)

\section{Associations between symptoms of PND and partial/ exclusive breastfeeding and formula feeding}

The results of the GEE models of PND with infant feeding practices are summarized in Table 4. The data on active smoking among mothers were insufficient, so it was not included in the GEE model. After controlling for covariates such as maternal age, maternal education attainment, household income, and pre-pregnancy BMI, depressive symptoms at 4 weeks postpartum were associated with the cessation of exclusive $(\beta=-0.049 ; 95 \% \mathrm{CI}$ : $-0.101,-0.004 ; P=0.047)$ and partial breastfeeding $(\beta=$ -0.082 ; 95\% CI: $-0.140-0.024 ; P=0.006)$ at 12 months postpartum. Moreover, symptoms of PND were associated with the introduction of formula for infants in the first year of life $(\beta=0.074 ; 95 \%$ CI: $0.014,0.134 ; P=$ $0.016)$. Women who initiated breastfeeding more than $24 \mathrm{~h}$ after giving birth were more likely to stop exclusive or partial breastfeeding $(\beta=-0.044$ and -0.035 , respectively; $P<0.05$ for both) than were women who breastfed their babies within $1 \mathrm{~h}$. In comparison to pre-pregnancy BMI between 18.5 and $23.9 \mathrm{~kg} / \mathrm{m}^{2}$, pre-pregnancy BMI less than $18.5 \mathrm{~kg} / \mathrm{m}^{2}$ was associated with both partial $(\beta$ $=-0.263)$ or exclusive breastfeeding cessation $(\beta=-$
0.198) and formula introduction $(\beta=0.213)$. Higher childbearing age (older than 35 years old) was associated with the cessation of breastfeeding for infants $(\beta=0.035)$. Additionally, compared to vaginal deliveries, caesarean deliveries were associated with a higher likelihood of formula introduction and the discontinuation of exclusive breastfeeding. No significant differences in exclusive or partial breastfeeding were found in the different maternal age groups. We also performed sensitivity analyses using the cut-off of $\geq 13$, and the results can be found in Additional file 1: Table S1. Our findings suggested that the associations between major postpartum depression and infant feeding outcomes were still significant in the sensitivity analyses.

\section{Discussion}

This study provides insight into infant feeding practices among women who experience depressive symptoms during the early postpartum period in the context of China. Our results suggested that after adjustments were made for potential confounders, symptoms of PND at 4 weeks postpartum were associated with increased risks of the absence of best-practice infant feeding practices,

Table 3 Comparisons of partial breastfeeding duration and formula introduction between mothers with and without symptoms of PND

\begin{tabular}{lccc}
\hline Variables & \multicolumn{2}{l}{$\begin{array}{l}\text { Symptoms of PND a } \text { (EPDS } \geq 10), \\
\text { median (IQR) }\end{array}$} \\
\cline { 2 - 3 } & No $(n=900)$ & Yes $(n=56)$ \\
\hline Duration of partial breastfeeding (months) & $8.02(3.43)$ & $6.32(3.96)$ & 0.008 \\
The introduction of formula (months) & $4.98(3.93)$ & $3.60(3.58)$ & 0.014 \\
\hline
\end{tabular}

a $P N D$ postnatal depression, IQR interquartile range 
Table 4 Results of the generalized estimating equations of symptoms of PND with infant-feeding outcomes across time

\begin{tabular}{|c|c|c|c|c|c|c|c|c|c|}
\hline \multirow[t]{2}{*}{ Variables } & \multicolumn{3}{|c|}{ Exclusive breastfeeding } & \multicolumn{3}{|c|}{ Partial breastfeeding } & \multicolumn{3}{|c|}{ Formula feeding } \\
\hline & $\beta$ & \multicolumn{2}{|l|}{$95 \% \mathrm{Cl}$} & $\beta$ & \multicolumn{2}{|l|}{$95 \% \mathrm{Cl}$} & $\beta$ & \multicolumn{2}{|l|}{$95 \% \mathrm{Cl}$} \\
\hline \multicolumn{10}{|c|}{ Maternal educational attainment } \\
\hline$\geq$ College graduate (ref) & - & - & - & - & - & - & - & - & - \\
\hline$\leq$ Junior school & -0.001 & -0.062 & 0.061 & -0.005 & -0.064 & 0.053 & -0.078 & -0.185 & 0.029 \\
\hline High school & -0.002 & -0.032 & 0.029 & -0.016 & -0.046 & 0.013 & 0.015 & -0.032 & 0.061 \\
\hline \multicolumn{10}{|l|}{ Maternal age (years) } \\
\hline $25-29$ (ref) & - & - & - & - & - & - & - & - & - \\
\hline$\leq 24$ & 0.027 & -0.018 & 0.071 & 0.036 & -0.006 & 0.078 & -0.022 & -0.089 & 0.046 \\
\hline $30-34$ & 0.000 & -0.024 & 0.024 & 0.001 & -0.023 & 0.024 & 0.005 & -0.029 & 0.038 \\
\hline$\geq 35$ & 0.020 & -0.012 & 0.053 & $0.035^{*}$ & 0.005 & 0.065 & -0.027 & -0.075 & 0.022 \\
\hline \multicolumn{10}{|l|}{ Pre-pregnancy BMI (kg/m²) } \\
\hline $18.5-23.9$ (ref) & - & - & - & - & - & - & - & - & - \\
\hline$<18.5$ & $-0.198^{*}$ & -0.333 & -0.064 & $-0.263^{*}$ & -0.394 & -0.133 & $0.213^{*}$ & 0.136 & 0.290 \\
\hline$\geq 24$ & -0.006 & -0.032 & 0.020 & 0.022 & -0.004 & 0.047 & -0.022 & -0.058 & 0.013 \\
\hline \multicolumn{10}{|l|}{ Household income (yuan) } \\
\hline $5001-10,000$ (ref) & - & - & - & - & - & - & - & - & - \\
\hline$\leq 2000$ & 0.072 & -0.008 & 0.152 & -0.027 & -0.091 & 0.037 & 0.072 & -0.008 & 0.152 \\
\hline $2001-5000$ & 0.019 & -0.012 & 0.050 & -0.010 & -0.031 & 0.011 & 0.019 & -0.012 & 0.050 \\
\hline$>10,000$ & 0.057 & -0.020 & 0.135 & -0.072 & -0.147 & 0.003 & 0.057 & -0.020 & 0.135 \\
\hline \multicolumn{10}{|c|}{ Initiation of breastfeeding (hours) } \\
\hline$<1$ (ref) & - & - & - & - & - & - & - & - & - \\
\hline $1-24$ & 0.005 & -0.028 & 0.038 & 0.010 & -0.020 & 0.039 & 0.003 & -0.043 & 0.048 \\
\hline$\geq 24$ & $-0.035^{*}$ & -0.074 & -0.005 & $-0.044^{*}$ & -0.083 & -0.004 & 0.037 & -0.014 & 0.089 \\
\hline \multicolumn{10}{|l|}{ Delivery mode } \\
\hline Vaginal delivery (ref) & - & - & - & - & - & - & - & - & - \\
\hline Cesarean delivery & $-0.043^{*}$ & -0.066 & -0.021 & -0.016 & -0.038 & 0.006 & $0.063^{*}$ & 0.031 & 0.094 \\
\hline \multicolumn{10}{|c|}{ Screen-positive symptoms of PND } \\
\hline No (ref) & - & - & - & - & - & - & - & - & - \\
\hline Yes & $-0.049^{*}$ & -0.101 & -0.004 & $-0.082^{*}$ & -0.140 & -0.024 & $0.074^{*}$ & 0.014 & 0.134 \\
\hline \multicolumn{10}{|l|}{ Gestational age (weeks) } \\
\hline $37-42$ (ref) & - & - & - & - & - & - & - & - & - \\
\hline $28-36$ & -0.009 & -0.055 & 0.038 & -0.029 & -0.105 & 0.047 & -0.003 & -0.052 & 0.047 \\
\hline \multicolumn{10}{|l|}{ Parity } \\
\hline Nulliparous (ref) & - & - & - & - & - & - & - & - & - \\
\hline Multiparous & -0.015 & -0.039 & 0.010 & -0.005 & -0.028 & 0.019 & 0.017 & -0.018 & 0.052 \\
\hline \multicolumn{10}{|l|}{ Miscarriage } \\
\hline No (ref) & - & - & - & - & - & - & - & - & - \\
\hline Yes & 0.010 & -0.011 & 0.031 & -0.017 & -0.038 & 0.005 & -0.006 & -0.037 & 0.025 \\
\hline \multicolumn{10}{|c|}{ Pregnancy-related complications } \\
\hline No (ref) & - & - & - & - & - & - & - & - & - \\
\hline Yes & 0.007 & -0.024 & 0.039 & 0.000 & -0.032 & 0.032 & -0.009 & -0.054 & 0.036 \\
\hline \multicolumn{10}{|c|}{ Passive smoking during pregnancy } \\
\hline No (ref) & - & - & - & - & - & - & - & - & - \\
\hline Yes & 0.014 & -0.021 & 0.049 & 0.013 & -0.019 & 0.044 & 0.016 & -0.031 & 0.064 \\
\hline
\end{tabular}


Table 4 Results of the generalized estimating equations of symptoms of PND with infant-feeding outcomes across time (Continued)

\begin{tabular}{|c|c|c|c|c|c|c|c|c|c|}
\hline \multirow[t]{2}{*}{ Variables } & \multicolumn{3}{|c|}{ Exclusive breastfeeding } & \multicolumn{3}{|c|}{ Partial breastfeeding } & \multicolumn{3}{|c|}{ Formula feeding } \\
\hline & $\beta$ & $95 \% \mathrm{Cl}$ & & $\beta$ & $95 \% \mathrm{Cl}$ & & $\beta$ & $95 \% \mathrm{Cl}$ & \\
\hline \multicolumn{10}{|c|}{ Using bottle/ nipple before breastfeeding } \\
\hline No (ref) & - & - & - & - & - & - & - & - & - \\
\hline Yes & -0.009 & -0.040 & 0.023 & -0.004 & -0.034 & 0.026 & 0.005 & -0.039 & 0.048 \\
\hline
\end{tabular}

* $P<0.05$

${ }^{\text {a }} \mathrm{BMI}$ body mass index, $\mathrm{Cl}$ confidence interval, $P N D$ postnatal depression

including the higher chance of exclusive breastfeeding cessation at 6 months or partial breastfeeding cessation and formula introduction at 12 months postpartum. These results highlight the importance of screening for symptoms of PND as one of the possible factors of adverse feeding outcomes.

The prevalence of mothers with symptoms of PND in Changsha (5.9\%) was found to be relatively low level in China $(4.70 \% \sim 43.12 \%)[29,30]$. One of the main reasons for the low PND rates in Changsha was the limited representativeness of the sample. The sample included in this study tended to be older, more educated, and of higher socioeconomic status compare to general mothers in China. Previous studies have suggested that these factors were protective factors preventing women from experiencing PND [41]. Additionally, in Chinese culture, given the inherent stigma of mental illness, concern for appearances may lead women to deny having PND and to refrain from seeking help from others [42], which might contribute to the low levels of depression in Changsha.

The present study showed that symptoms of PND were associated with the discontinuation of exclusive or partial breastfeeding. Consistent with our findings, previous studies demonstrated that mothers with PND were at higher risk of shorter full/partial breastfeeding duration [15, 43, 44]. McLearn et al. reported that mothers with depressive symptoms were less likely to continue breastfeeding through two to 4 months postpartum than were mothers without depressive symptoms [45]. Using an EPDS score $>10$ as the cut-off point for PND, Galler et al. found that depressive symptoms at 7 weeks postpartum could predict breastfeeding practices at 7 weeks, 3 months, and 6 months postpartum. However, these associations became non-significant at 6 months postpartum [46]. Our findings also suggested that depressive symptoms in the early postpartum period may be associated with the early formula introduction. Using the same cut-off used in our study, Gagliardi et al. found that mothers with PND were more likely to bottle feed at 3 months and that the odds of bottle-feeding increased with EPDS scores [47]. Consistent with a previous study [48], we found that breastfeeding initiation was associated with infant feeding outcomes. The study also discovered that caesarean deliveries were related to the supplementation of formula and the discontinuation of breastfeeding for infants.

The following are possible explanations for the associations between the high levels of depression symptoms and poor feeding outcomes. Postpartum depression might cause negative effects on maternal self-esteem and cognition [49]. Moreover, women with depressive symptoms may have more inadequate interactions with their new-borns, such as less touching, sensitivity, and skin to skin, which in turn increases the risk of breastfeeding difficulties, lack of confidence in their ability to breastfeed their babies, and decreased satisfaction related to their infant feeding practices [50].

This study provides more evidence for the role of postpartum depressive symptoms in feeding behaviours, especially for the Chinese population. The EPDS is a simple and reliable screening instrument for the early detection of depression in the postnatal period. Based on this screening instrument, our results highlight that even small benefits are achievable in terms of preventing nonoptimal feeding practices by reducing the incidence of postpartum depression. Targeted and appropriate interventions, such as psychosocial assessment and social support, both from health professionals and from family and friends, including women's partners/husbands, should be provided for mothers with symptoms of PND, especially for women of low socioeconomic status, as they are at increased risk for depression.

\section{Strengths}

This study has several strengths. This study used a prospective longitudinal birth cohort. Thus, the data for feeding practices were collected prospectively; this design helps evaluate the direction of the proposed relationship between symptoms of PND and infant feeding behaviours [2]. A number of potential covariates identified from the prior literature were included in multivariate models. Moreover, the GEE model is suitable for analysing the longitudinal data, which can minimize the accumulation of Type I error from multiple endpoint comparisons [51]. One of the strengths of GEE is that we do not need to identify the exact distribution of the various breastfeeding outcomes across time but rather only need to provide the mean structure for the GEE model to perform the analysis [52]. 


\section{Limitations}

The study has some limitations. The sample included in the current study is rather homogeneous, as participants are predominantly from the city, are older and are well educated with a high average household income, representing a healthier segment of the population. Thus, the generalization of the results to the general population of childbearing-aged women in China should be exercised with caution. Although we had adjusted for a range of potential confounders of feeding practices, there are still many other relevant prenatal and perinatal factors that were not included in our analysis, such as prenatal depressive symptoms, adverse life events, social support, partner relationship, breastfeeding self-efficacy, and pre-birth intentions to breastfeed. These unmeasured factors may affect the actual associations between maternal symptoms of PND and feeding practices. Additionally, postpartum depressive symptomatology in this study was based on mothers' self-report. Future studies should include diagnostic interviews to ascertain PND clinically. Finally, this study revealed that the symptoms of PND at 4 weeks postpartum were associated with infant feeding outcomes at 12 months postpartum, but these associations must be interpreted cautiously because they were generated at only one evaluation of the depressive symptoms at 4 weeks postpartum, which might not be enough to determine the apparent longitudinal association. Hence, a well-designed, large-scale cohort study, which can provide a clear operationalized definition for infant feeding outcomes and screened symptoms of PND, should be further conducted to explore the longitudinal association between symptoms of PND and breastfeeding practices.

\section{Conclusion}

In summary, our findings suggest that among mothers, symptoms of PND at 4 weeks postpartum are associated with the non-optimal infant feeding practices in the 12 months of delivery in the context of China. These results support the importance of screening mothers with depressive symptomatology during the first few weeks after childbirth. Early psychosocial assessment and social support should be offered to mothers in the early postpartum period to indirectly prevent adverse breastfeeding outcomes.

\section{Supplementary information}

Supplementary information accompanies this paper at https://doi.org/10. 1186/s12884-019-2559-1.

Additional file 1: Table S1. Results of the generalized estimating equations of screen-positive for major PND ${ }^{\text {a }}$ (cutoff $\geq 13$ ) with infantfeeding outcomes across time

\section{Abbreviations}

CHMIS: Community Health Management Information System;

CHSCs: Community Health Service Centers; Cl: Confidence interval;
EPDS: Edinburgh Postnatal Depression Scale; GEE: Generalized estimating equation; IQR: Interquartile range; PND: Postnatal depression; WHO: World Health Organization

\section{Acknowledgments}

This work was supported by the Health and Family Planning Commission, Sifangping Street Community Health Center, Dongfeng Road Street Community Health Center and Xinhe Street Community Health Center of Changsha in Hunan province. The authors are grateful to all the CHSC's coordinators, for their help with the field procedures.

\section{Authors' contributions}

Contributions are briefly explained as follows. STT conceived and designed the study, performed the data analyses, wrote the original draft, and revised it critically for important intellectual content. YY the corresponding author, led the research and revised the original draft and decided final approval of the version to be submitted. GX, CC, LL, WXL, TQL, YF helped to supervise the field activities and to complete the acquisition of data; $C G$ and $\mathrm{HQ}$ directed its implementation, including quality assurance and control. All authors read and approved the final manuscript.

\section{Funding}

This work was supported by the National Natural Science Foundations (NSFC) of China (Grant reference number: 81673276). Tingting Sha is supported by a graduate student scientific research innovation project of Central South University (Grant reference number: 2018zzts237). The funder had no role in the design of the study, data collection, analysis,

interpretation of the data and preparation of the manuscript.

\section{Availability of data and materials}

The datasets used and/or analyzed during the current study are available from the corresponding author on reasonable request.

\section{Ethics approval and consent to participate}

This study was conducted under the approval of the independent Ethics Committee (EC) of the clinical pharmacology Institute of Central South University (CTXY-130041-3-2). The participants who met the inclusion criteria and signed the informed consent were involved.

Consent for publication

Not applicable

\section{Competing interests}

The authors declare that they have no competing interests.

Received: 18 December 2018 Accepted: 14 October 2019

Published online: 28 October 2019

\section{References}

1. Howard LM, Molyneaux E, Dennis CL, Rochat T, Stein A, Milgrom J. Non-psychotic mental disorders in the perinatal period. Lancet. 2014; 384:1775-88.

2. Pope CJ, Mazmanian D. Breastfeeding and postpartum depression: an overview and methodological recommendations for future research. Depress Res Treat. 2016;2016:4765310.

3. Diagnostic and Statistical Manual of Mental Disorders. 5th ed. Washington DC: I American Psychiatric Publishing; 2013.

4. Grote NK, Bridge JA, Gavin AR, Melville JL, lyengar S, Katon WJ. A metaanalysis of depression during pregnancy and the risk of preterm birth, low birth weight, and intrauterine growth restriction. Arch Gen Psychiatry. 2010; 67:1012-24.

5. Clare CA, Yeh J. Postpartum depression in special populations: a review. Obstet Gynecol Surv. 2012:67:313-23.

6. Wisner KL, Sit DK, McShea MC, Rizzo DM, Zoretich RA, Hughes $C L$, et al. Onset timing, thoughts of self-harm, and diagnoses in postpartum women with screen-positive depression findings. JAMA Psychiat. 2013;70:490-8.

7. Pope CJ, Xie B, Sharma V, Campbell MK. A prospective study of thoughts of self-harm and suicidal ideation during the postpartum period in women with mood disorders. Arch Womens Ment Health. 2013;16:483-8.

8. World Health Organization. Exclusive breastfeeding. 2018. http://www.who. int/nutrition/topics/exclusive_breastfeeding/en/. Accessed 15 Dep 2018. 
9. Eidelman Al, Schanler RJ, Johnston M, Landers S, Noble L, Szucs K, et al. Breastfeeding and the use of human milk. Pediatrics. 2012;129:e827-41.

10. World Health Organization. Promoting proper feeding for infants and young children. 2018. http://www.who.int/nutrition/topics/infantfeeding/ en/. Accessed 15 Dep 2018.

11. Victora CG, Bahl R, Barros AJ, Franca GV, Horton S, Krasevec J, et al. Breastfeeding in the 21st century: epidemiology, mechanisms, and lifelong effect. Lancet. 2016;387(10017):475-90

12. Figueiredo $B$, Canario C, Field T. Breastfeeding is negatively affected by prenatal depression and reduces postpartum depression. Psychol Med. 2014:44:927-36

13. Hahn-Holbrook J, Haselton MG, Dunkel Schetter C, Glynn LM. Does breastfeeding offer protection against maternal depressive symptomatology?: a prospective study from pregnancy to 2 years after birth. Arch Womens Ment Health. 2013;16:411-22.

14. Dias CC, Figueiredo B. Breastfeeding and depression: a systematic review of the literature. J Affect Disord. 2015;171:142-54

15. Dennis CL, McQueen K. The relationship between infant-feeding outcomes and postpartum depression: a qualitative systematic review. Pediatrics. 2009; 123:e736-51.

16. Nis,hioka E, Haruna M, Ota E, Matsuzaki M, Murayama R, Yoshimura K, et al. A prospective study of the relationship between breastfeeding and postpartum depressive symptoms appearing at 1-5 months after delivery. Pediatrics. 2009;123:e736-51.

17. Dennis $\mathrm{CL}$, McQueen K. Does maternal postpartum depressive symptomatology influence infant feeding outcomes? Acta Paediatr. 2007;96:590-4.

18. Taveras EM, Capra AM, Braveman PA, Jensvold NG, Escobar GJ, Lieu TA. Clinician support and psychosocial risk factors associated with breastfeeding discontinuation. Pediatrics. 2003;112:108-15.

19. Kehler HL, Chaput KH, Tough SC. Risk factors for cessation of breastfeeding prior to six months postpartum among a community sample of women in Calgary. Alberta Can J Public Health. 2009;100:376-80.

20. McCarter-Spaulding D, Horowitz JA. How does postpartum depression affect breastfeeding? MCN Am J Matern Child Nurs. 2007;32:10-7.

21. Chung EK, McCollum KF, Elo IT, Lee HJ, Culhane JF. Maternal depressive symptoms and infant health practices among low-income women. Pediatrics. 2004;113:e523-9.

22. Annagur A, Annagur BB, Sahin A, Ors R, Kara F. Is maternal depressive symptomatology effective on success of exclusive breastfeeding during postpartum 6 weeks? Breastfeed Med. 2013;8:53-7 Epub 2012/10/09.

23. Hasselmann MH, Werneck GL, Silva CV. Symptoms of postpartum depression and early interruption of exclusive breastfeeding in the first two months of life. Cad Saude Publica. 2008;24(Suppl 2):S341-52.

24. Haga SM, Lisøy C, Drozd F, Valla L, Slinning K. A population-based study of the relationship between perinatal depressive symptoms and breastfeeding: a cross-lagged panel study. Arch Womens Ment Health. 2018;21:235-42.

25. Ip S, Chung M, Raman G, Chew P, Magula N, DeVine D, et al. Breastfeeding and maternal and infant health outcomes in developed countries. Evid Rep Technol Assess. 2007;153:1-186.

26. Bogen DL, Hanusa BH, Moses-Kolko E, Wisner KL. Are maternal depression or symptom severity associated with breastfeeding intention or outcomes? J Clin Psychiatry. 2010;71:1069-78.

27. Ke J, Ouyang YQ, Redding SR. Family-centered breastfeeding education to promote Primiparas' exclusive breastfeeding in China. J Hum Lact. 2018;34:365-78

28. Tang $L$, Lee $A H$, Binns $C W$. Factors associated with breastfeeding duration: a prospective cohort study in Sichuan Province, China. World J Pediatr. 2015; $11: 232-8$.

29. Zhang X, Zhao G, Chen LJ, Di j. Onset, prognosis and effect factors of postpartum depression. Matern Child Health Care China. 2009;24:3062-5 [in Chinese].

30. Lee D, Yip A, Chiu H, Leung T, Chung T. A psychiatric epidemiological study of postpartum Chinese women. Am J Psychiatry. 2001;158:220-6.

31. Difrisco E, Goodman KE, Budin WC, Lilienthal MW, Kleinman A, Holmes B. Factors associated with exclusive breastfeeding 2 to 4 weeks following discharge from a large, urban, academic medical center striving for babyfriendly designation. J Perinat Educ. 2011;20:28-35.

32. Exclusive breastfeeding for six months best for babies everywhere. World Health Organization. 2011. http://www.who.int/mediacentre/news/ statements/2011/breastfeeding_20110115/en/. Accessed 15 Dep 2018.
33. Indicators for assessing infant and young child feeding practices. World Health Organization. 2008. http://www.who.int/maternal_child_adolescent/ documents/9789241596664/en/. Accessed 15 Dep 2018.

34. Lee DT, Yip SK, Chiu HF, Leung TY, Chan KP, Chau IO, et al. Detecting postnatal depression in Chinese women. Validation of the Chinese version of the Edinburgh postnatal depression scale. Br J Psychiatry. 1998;172:433-7.

35. Deng AW, Xiong RB, Jiang $\Pi T$. A study of the critical value of Edinburgh Postnatal depression scale in delivery women in urban Areas in Guangzhou. Clinical misdiagnosis \& Mistherapy. 2014;27:101-4. [in Chinese]

36. Wang Y, Guo X, Lau Y, Chan KS, Yin L, Chen J. Psychometric evaluation of the mainland Chinese version of the Edinburgh postnatal depression scale. Int J Nurs Stud. 2009;46:813-23.

37. Murray L, Carothers AD. The validation of the Edinburgh post-natal depression scale on a community sample. Br J Psychiatry. 1990;157:288-90.

38. Cox JL, Holden JM, Sagovsky R. Detection of postnatal depression. Development of the 10-item Edinburgh postnatal depression scale. $\mathrm{Br}$ J Psychiatry. 1987;150:782-6.

39. Matthey S, Henshaw C, Elliott S, Barnett B. Variability in use of cut-off scores and formats on the Edinburgh postnatal depression scale: implications for clinical and research practice. Arch Womens Ment Health. 2006;9:309-15.

40. Dennis CL, Gagnon A, Van Hulst A, Dougherty G. Predictors of breastfeeding exclusivity among migrant and Canadian-born women: results from a multiCentre study. Matern Child Nutr. 2014;10:527-44.

41. Liu S, Yan Y, Gao X, Xiang S, Sha T, Zeng G, et al. Risk factors for postpartum depression among Chinese women: path model analysis. BMC Pregnancy Childbirth. 2017:17:133

42. Lau Y, Wong DF. Are concern for face and willingness to seek help correlated to early postnatal depressive symptoms among Hong Kong Chinese women? A cross-sectional questionnaire survey. Int J Nurs Stud. 2008:45:51-64.

43. Hamdan A, Tamim H. The relationship between postpartum depression and breastfeeding. Int J Psychiatry Med. 2012;43:243-59.

44. Brown A, Rance J, Bennett P. Understanding the relationship between breastfeeding and postnatal depression: the role of pain and physical difficulties. J Adv Nurs. 2016;72:273-82.

45. McLearn KT, Minkovitz CS, Strobino DM, Marks E, Hou W. Maternal depressive symptoms at 2 to 4 months postpartum and early parenting practices. Arch Pediatr Adolesc Med. 2006;160:279-84.

46. Galler JR, Harrison RH, Biggs MA, Ramsey F, Forde V. Maternal moods predict breastfeeding in Barbados. J Dev Behav Pediatr. 1999;20:80-7.

47. Gagliardi L, Petrozzi A, Rusconi F. Symptoms of maternal depression immediately after delivery predict unsuccessful breast feeding. Arch Dis Child. 2012;97:355-7.

48. Seimyr L, Edhborg M, Lundh W, Sjogren B. In the shadow of maternal depressed mood: experiences of parenthood during the first year after childbirth. J Psychosom Obstet Gynaecol. 2004;25:23-34.

49. Henderson JJ, Evans SF, Straton JA, Priest SR, Hagan R. Impact of postnata depression on breastfeeding duration. Birth. 2003:30:175-80.

50. Flores-Quijano ME, Cordova A, Contreras-Ramirez V, Farias-Hernandez L, Cruz Tolentino M, Casanueva E. Risk for postpartum depression, breastfeeding practices, and mammary gland permeability. J Hum Lact. 2008;24:50-7.

51. Huh D, Flaherty BP, Simoni JM. Optimizing the analysis of adherence interventions using logistic generalized estimating equations. AIDS Behav. 2012:16:422-31.

52. Molenberghs G. Generalized estimating equations. Notes on the choice of the working correlation matrix. Methods Inf Med. 2010:49:419-20.

\section{Publisher's Note}

Springer Nature remains neutral with regard to jurisdictional claims in published maps and institutional affiliations. 